\title{
Exploration into the Factors Affecting the Coverage of Household Latrines in Kagera, Tanzania
}

\author{
Article by James Barongo Bashweka \\ Ph.D in Public Health, Texila American University, Tanzania \\ E-mail: jbarongo2004@yahoo.co.uk
}

\begin{abstract}
Low coverage of household latrines in the Kagera Region of Tanzania continues to exist despite past and current interventions to improve the situation. A limited understanding of the reasons for the low coverage restricted solving of this problem. The research which aimed to explore the perceptions of community members and latrine promoters was sought to increase understanding of this problem.

Methods: Study designed was an exploratory qualitative approach that employed two qualitative research methods: focus group discussions and in-depth interviews. Focus groups discussion involved elderly community members and Ward Development Committee members who are leaders and latrine promoters. In-depth interviews involved key informants whose job descriptions includes the promotion of household latrines. Ethical approval was obtained from University of Western Cape and authorisation to conduct the study from the Kagera Regional Administrative Secretary.

Results: Content analysis revealed a thick description of respondent's perceptions in relation to factors which affect the coverage of household latrines in the Kagera Region. Interlinked factors were revealed including low community involvement and participation, poverty, cultural beliefs and taboos, gender disparity, low technical capacity of latrine promoters and poor packaging.

Conclusion: This study revealed myriad factors which affect the coverage of household latrines in Kagera Region of Tanzania. Recommendations were put forward including adoption of an integrated approach, empowerment of members, and provision of capacity building interventions for the key latrine promoters. Insights gained through this study could contribute towards improving the coverage of household latrines in the Kagera Region of Tanzania.
\end{abstract}

Keywords: Low coverage, household, latrine, sanitation, factors, promotion, perception, Muleba District, Kagera Region, Tanzania

\section{Background information}

Sanitation is an important element of health which was included as part of the Alma Ata Declaration on Primary Health Care, Health For All by the Year 2000 (WHO, 1978). This took place in the Alma Ata Declaration to plan for comprehensive Primary Health Care package advocated included basic sanitation for all people (WHO, 1978). It was anticipated that sanitation promotion would be implemented according to the Primary Health Care Principles of equity, accessibility, health promotion, prevention, intersectoral action, community involvement, decentralisation, integration and coordination of health activities (WHO, 1978). However, this did not yield the intended results until the end of the 20th century. It was claimed this due to poverty and a concentration on vertical programmes rather than an integrated Primary Health Care approach (Werner, 1995). Inappropriate stratagies such as distribution of 400 million packets of Oral Rehydration Therapy each year as part of a campaign to reduce children's deaths from diarrhoea, while over 133 million children were still dying annually in developing countries due to poor sanitation was another limitation.

Another significant global strategy that relates to sanitation was the United Nations Millennium Development Goals (MDGs) initiated in 2000 (UNDP, 2000).Within this strategy are eight development targets due to be achieved by 2015. Sanitation was incorporated within goal number seven (MDG7), which was to halve the number of people with no access to safe drinking water and 
Texila International Journal of Public Health

Volume 4, Issue 4, Dec 2016

sanitation by 2015. All 191 United Member States signed the MDGs Declaration in September 2000 (UNDP, 2000). The MDGs committed all world leaders to ensure environmental sustainability through a global partnership for development. In response to MDG7, the Government of Tanzania adopted the National Strategy for Growth and Poverty Reduction (Chaggu, 2009). Through this Government commitment, various sanitation operation targets were set to be achieved by 2010. This included the fulfilment of target 10 of MDG7 for the improvement of the health and socio-economic status and the quality of lives of people particularly children and women. In addition, Vision 2025and of the Government of Tanzania.

However, MDG7 targets on sanitation was not achieved and expected to long term challenge as it was noted by UNDP (2006) that due to current sanitation trend, Sub-Saharan African countries will only reach the Millennium Development Goal Water target in 2040 and the sanitation target in 207. The author therefore called for concerted action from all stakeholders in order to achieve MDG set targets.

Kagera region Tanzania, it was reported by Regional Secretariat and Regional Health Management Team (2012), reported that ownership of safe a household latrine was a major challenge with low coverage persistently dropping over the past four years. Statistically, in (2012) it was reported that household latrine coverage in Kagera region was 50 percent. Although this percentage rate was above the national coverage of 47 percent (MOHSW, 2009), it had decreased over the previous three years from 56.3 percent in 2008, to 52.6 percent in 2009, and 50 percent in 2010

It was further reported in the Council's Comprehensive Health Plan (2010/12) that among the top five health problems are communicable diseases including diarrhoeal diseases, worm infestation and malaria. These diseases are all related to an unsanitary environment particularly low coverage of household's latrines. This means that a high proportion of households are still practicing unsafe faecal disposal, such as open defecation on their farming plots or bushes. This type of defecation is unhygienic; it contaminates the air, the water and the general environment, leading to the spread of germs which cause diarrhoeal diseases. These diseases constituted 30 percent of all visits to the outpatient departments in the region (Region Secretariat and Region Health Management Team, 2010). The above state of affairs triggered the mind of research to conduct an explorative study in Muleba district which is one of 8 district in Kagera region as a -partial fulfillment of the requirements for the degree of Masters in Public Health at School of Public Health, University of Western

The Muleba District was chosen for this study for the following reasons: District Health Profiles from 2009 to 2011 (Council Health Management Team, 2013) estimated that, in total, only 52.4 percent of households in the Muleba District had hygienic latrines, which is far below the national target set to achieve 82 percent in rural areas and 100 percent in urban areas by 2015. The Muleba District prioritised water and basic sanitation in their council health plans and there have been several interventions to provide this to residents in this district. However, it is these interventions appeared to have had little impact on changing people's lifestyles and social behaviour towards the construction of latrines.

\section{Consequences of low coverage of latrines in the kagera region}

The consequences of low coverage of household latrines are numerous and include high morbidity and mortality levels due to diseases such as worm infestations and diarrhoea. Population Services International in Tanzania (2004) estimated that Tanzanian children suffer three to four episodes of diarrhoea per year resulting in it being a leading cause of morbidity and mortality for children under five years old. Morbidity data for all Kagera District Councils shows a high prevalence of faecal oral diseases, predominantly worms and diarrhoeal diseases, with an annual rate of 64/1000 (2012). This indicates that many people become sick due to sanitation related diseases, leading to unnecessary suffering, morbidity and mortality. In 2011, children under five years of age reporting with worm infestations and diarrhoeal diseases were 7.1 percent and 4.4 percent respectively. Outpatient cases accounted for 3.6 percent and 4.6 percent among adults and children under-five respectively. It was 
further reported that 4.9 percent of the deaths among children under five years of age were due to diarrhoeal diseases; making this the fourth highest killer of children under-five. It was also reported that 9.4 percent of adult deaths were due to diarrhoeal diseases (Region Secretariat and Region Health Management Team, 2011). The concerns went beyond the morbidity and mortality figures. The Regional Secretariat and Regional Health Management Team (2011) also claimed that the low coverage of household latrines affects community members economically. Many people become ill frequently resulting in unnecessary suffering, loss of productive time and money to cater for the treatment needed. This is due to the costs involved in taking care of those affected, such as medical care fees, drugs and laboratory tests. It also means an added workload for health institutions which are already overstretched and understaffed. This was a key rationale for the researcher to embark in this study.

\section{Key information on study area}

The Kagera Region is one of the 24 regions of the United Republic of Tanzania. It lies in the North West corner of the country, along the shores of Lake Victoria. The region covers a total area of 39,627 $\mathrm{km}^{2}$ comprising $28,388 \mathrm{~km}^{2}$ of land and $11,239 \mathrm{~km}^{2}$ of water; the largest area of water in the country.

The Kagera Region is located between $1-3^{\circ}$ south of the Equator, at a longitude of $30-32^{\circ}$ east of Greenwich. It lies at an altitude of 1100-1800 meters above sea level. The region has an equatorial type of climate with an average bi-annual rainfall of $800-1200 \mathrm{~mm}$ and a temperature range of between $9-32^{\circ} \mathrm{C}$.

Administratively, the Kagera Region deals with a total population of 2,513,188 distributed through seven districts namely, Biharamulo, Bukoba, Muleba, Ngara, Kyerwa, Missenyi, Karagwe and Bukoba municipal council. Population is composed of various tribe include Haya, Nyambo, Hangaza, Subi and Sukuma and 70 percent of the inhabitants are small-scale farmers These form the livelihood of community members. The majority of the buildings in the area are constructed using wood and mud walls, and are roofed with either grass thatch or iron sheets. (Kagera Regional Secretariat and Regional Health Management Team, 2013). These levels and the relevant bodies operating at each level are discussed below and are summarised in Figure 2.

\section{Levels 0 and 1}

Levels 0 and 1 are the levels of individual households and the community. It is at these levels that policies and guidelines for improvement need to be implemented and/or enforced. These levels represent the target groups and beneficiaries of health services, including latrine promotion interventions. This is where all health efforts are directed to improve the health status and wellbeing of people. 
Texila International Journal of Public Health

Volume 4, Issue 4, Dec 2016

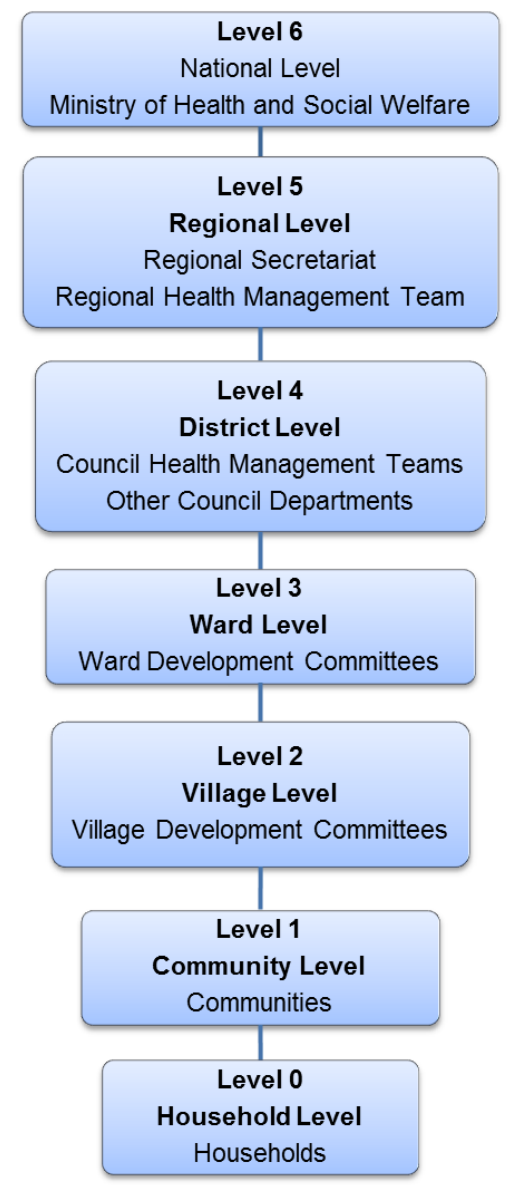

FIGURE 1. Levels involved in latrine promotion

\section{Levels 2 and 3}

The village and ward levels, under VDCs and WDCs, are close to households and the community. They are responsible for the day-to-day functions of all development issues, including latrine promotion. These levels require support from the district, level 4 , in order to be effective in supporting levels 0 and $l$ as it is the district that is responsible for policy and law enforcement.

\section{Level 4}

Level 4 is the district level where the CHMT and other council departments, such as health, education, agriculture, public works, and water and community development are found. Level 4 links Regional and Central Government with lower levels and provides technical support to wards and the village level. The CHMT, which is a top district council body, requires technical capacity and integrity in order to support levels 2 and 3. In addition, level 4 should be supported and supervised by level 5.

\section{Level 5}

The Regional Secretariat and RHMT operate at level 5, the regional level. This level is involved in policy translation and offers technical support to the district level. Level 5 also represents the Ministry of Health and Social Welfare which plays a supervisory role and provides guidelines to the CHMTs at level 4. 


\section{Level 6}

Level 6 is the Ministry of Health and Social Welfare, a top organ that works in collaboration with other bodies to develop all policies, guidelines and protocol for latrine promotion. This level also provides financial and technical assistance to the regions, level 5 (The United Republic of Tanzania Ministry of Health, 1998).

\section{Type of sanitation in kagera region}

Sanitation is one component of environmental hygiene that includes the collection and disposal of human excreta, in particular urine and faeces (UNICEF, 2008). Sanitation has two systems which are classified in two categories. The first is an onsite sanitation system, where human excreta is retained and treated on the site of defecation in a way that is hygienic and does not adversely affect the environment (WHO, 2010). The second system is an off-site sanitation system, where human excreta is removed from the defecation site by conventional sewerage and then treated and disposed of through a small bore sewer. It involves treatment and skilled operators for management, operation and maintenance and requires large quantities of water for flushing. This off-site sanitation system is not suitable in peri-urban and rural areas with water supply shortages (WHO, 2010). Onsite and off-site sanitation systems are practiced in the Kagera Region. Onsite systems are commonly used by the rural population and off-site systems are common in urban areas, for the reasons expressed above. Though there is no uniformity in the types of latrines promoted in the Kagera Region, the most common are the improved pit latrine and the ventilated improved pit latrine. Improved latrines should comprise a deep pit or trench latrine that is about $(0.76-1.22 \mathrm{~m})$ wide and 6-(1.83-3.05 m) deep. (Friend of Lake Victoria

\section{Study design}

The study type selected was that of an exploratory study aimed at understanding the respondents' perceptions of the factors contributing to the low coverage of household latrines. Two qualitative research methods were used: Focus Group Discussions (FGDs) and In-depth Interviews. This qualitative approach facilitated the collection of information that provided an understanding of the respondents' awareness and knowledge about the coverage of household latrines, based on their own experience.

\section{The aim of this study}

The research aimed to explore the perceptions of community members and latrine promoters on the reasons for the low coverage of latrines in order to increase the understanding of this issue, and look for more effective solutions. This in turn, should result in an improvement in the health status of community member in Kagera Region in general.

\section{Specific objectives}

01. To assess the perceptions of community members about the importance of latrines as a basic household structure.

02. To explore the perceptions of latrine promoters and community members regarding the role of latrine promoters in improving the coverage of household latrines in the Kagera Region.

03. To explore the views of community members and latrine promoters about the enabling and hindering factors for improved coverage of household latrines in Kagera.

04. To explore the approaches that could be used to improve household latrine coverage in the Kagera Region

\section{Sampling and study population}

The study population for the first FGD included influential, elderly people who have an informal leadership role in women or men's groups at a community level. As they come from informal 
community groups at level. They are beneficiaries and consumers of latrine promotion services. They are considered a homogenous, informal group because they share the same information, community norms and experiences, and come from the same geographical location. The sample from this population group constituted six people (one woman and five men). The selection criteria included being aged between 50 and 60 years old, living permanently in the wards and owning a house. They were purposely selected with the assistance of the Ward Executive Officer and the Ward Counsellor. Based on their experience in the community, they were considered to have sufficient information about latrine issues. These people were also knowledgeable about different factors in terms of the social, cultural and community norms in relation to defecation, faecal disposal and latrines. They were therefore considered to be information rich subjects.

The study population for the second FGD consisted members of Village Development Committees (VDCs) and Ward Development Committees (WDCs) who are latrine promoters at levels lower community level. Given their roles, they are supposed to take an active role in latrine promotion, including providing technical support and the enforcement of law, policies and guidelines to the community members and families at levels. The sample for this FGD was six members of the VDC and WDC. These were three women and three men aged between 25 to 60 years old. They were considered a homogenous sample because they have shared roles and responsibilities, and because they could be considered information rich in relation to the promotion of household latrines at ward and village levels.

The study population for the in-depth interviews comprised health and development managers from the District Council at level 4 of health services implementation (CHMT) and the Regional Secretariat and RHMT at level 5 of health services implementation (Figure 1). All have been involved in latrine promotion for more than 10 years and were selected based on their qualifications. The two respondents from district level were selected with the assistance of the District Executive Director who is in charge of all district staff. The regional level respondent was selected with the assistance of the Regional Medical Officer who is the chairperson of the RHMT. Basically the study concentrated at ward level where most of respondent were drawn and few from district and Region level as the following narrated structures.

\section{Data collection}

The researcher discussed the study with the District Executive Director and District Administrative Secretary and sought suggestions of the key informants to select for the in-depth interviews. The Ward Executive Officer was also consulted before the finalising the selection the respondents for the in-depth interviews. All the respondents were consulted to seek their willingness to participate in the research. They were all briefed on the research and an arrangement was made with them about the dates and times for individual, face-to-face interviews.

The consultation on the selection of FGD respondents took place with the Ward Executive Officer. Again appropriate times and places were arranged to conduct the discussions. The researcher was accompanied by a research assistant during both the focus groups discussions and in-depth interviews. The research assistant took notes and observed the respondents for aspects such as body language and their level of participation. In addition, the researcher used a tape recorder to record the discussion, having had this agreed to by the respondents. The recorded information was later transcribed and translated into English.

Research tools included a question guide for the FGDs and semi-structured questionnaires for the in-depth interviews. These tools were in Kiswahili which is the national and official language of Tanzania. Kiswahili was used throughout the discussion with the respondents. However, in some instances, Kihaya was used to clarify issues when it was deemed necessary by both the researcher and the respondents. This did not create any problem since the researcher and research assistant are conversant in both Kiswahili and Kihaya. 


\section{Data analysis}

As is the nature of qualitative research, data analysis was done concurrently with data collection in order to adapt the subsequent focus groups and interviews on the basis of previously captured and analysed information. The researcher employed a thick description of data from the FGDs and individual interviews and collated the information accordingly. This was followed by content analysis according to themes in relation to the factors affecting the low coverage of household latrines and possible solutions were drawn from this data. Thereafter coding and categorising of data was done to produce the meaning of respondents' responses.

\section{Ethical considerations}

The researcher obtained from the Ethical Committee at the University of Western Cape also requested permission from the Regional Administrative Secretary of the Kagera Region. Participation was voluntary and consent was sought from the individuals and groups who were interviewed. Individual responses and views were respected and all participants were assured of confidentiality and anonymity by not linking collected information to the person's name or other identification such as his/her address. In addition, the completed information was kept by the researcher in safe custody. Respondents were provided with letters in Kiswahili explaining the nature of the study, requesting their voluntary participation and assuring them about confidentiality. Consent forms were translated in Kiswahili and each participant signed it as proof of their willingness to participate, as well as their right to refuse to participate in the research or withdraw from the study at any time with no implications.

\section{Limitations}

The small sample size was a constraint due to the nature of the mini-thesis. However, the researcher adopted the principles and nature of qualitative research whereby detailed discussion and thick description provided valid and credible results. Triangulation was also applied as a means of increasing rigor which included methodological triangulation, data sources triangulation, theoretical triangulation through literature review.

\section{Relevance of the study topic}

As regards to the relevance of the topic, it was revealed and acknowledged by all FGDs and indepth interview responses that the topic was relevant. This was also supported by the literature review. In addition, responses indicated that household latrines are an important aspect in the maintenance of health and social integrity. It was further argued by most of the respondents that, though the topic is important, it had been overlooked and they therefore suggested the need for urgent attention. Given that the low coverage of household latrines is an issue of concern to both the community members and latrine promoters; this provided an opportunity for the latrine promoters to initiate a dialogue on how best to raise the level of household latrine coverage in the Kagera Region. It can also be argued that acknowledgement of this topic by the respondents can be seen as a clear indication that people are aware of this problem but, have probably lacked the opportunity to discuss it.

\section{Respondents' knowledge on sanitation problems}

The study also revealed respondents were aware about this problem, FGD respondents estimated that only one out of ten households in the vicinity owns a latrine and that even when latrines are available they are poor in terms of quality and physical appearance. This study detected several overlapping themes in relation to sanitation coverage. These themes included community involvement, economic status, culture and taboos, gender disparity, lack of motivation among the community members, knowledge on the health benefits, political factors, capacity of promoters and promotion strategies. These findings demonstrate the prevailing high level of knowledge and 
understanding of the problem among respondents; the central question however, is why latrine coverage is still a challenge despite this knowledge. The same challenge was identified by the Hesperian Foundation (2005) which found that the relationship of knowledge and the perceived benefits from latrines among community members are not always connected with the health benefits because some people are primarily interested in clean toilets, improved hygiene and privacy.

\section{Lack of community involvement}

This study revealed that apart from receiving information from health workers and leaders instructing people to construct latrines, communities are not adequately involved in latrine promotion. In addition, it was learnt that not enough support has been given at a community level to assist in latrine construction. It was further revealed that due to low community involvement, latrine promotion or education was considered to be the role of employed people and not the role of community members. Furthermore, it was found that community members are not aware of the types of latrines that exist and are also not involved in selecting which types to construct in their community. The study also found that people are told to construct latrines as a routine measure instead of enabling them to understand the appropriate type of latrines to construct. It was further found that latrine packaging, such as the promotion of VIPs, lacked the involvement of community members during their selection. A similar weakness was discussed by other researchers whereby most of interventions were noted to be of top-down approached and based on the superficial involvement of community members community. A similar weakness was discussed by Sah and Negussia (2008) that most of the sanitation promotion in Africa are of top-down and based on the superficial involvement of community members. The authors also noted that promoters emphasised coverage rather than the improvement of sanitary behaviours. There is also the tendency for promoters to only focus on hardware rather than combining it with software, which would include information, education and communication (IEC) and behaviour change communication (BCC) events (DFID, 2002). Moreover, it was emphasised by the Ministry of Foreign Affairs of the Netherlands (2012) and the African Ministry Council on Water (2011) that community led heath education in latrine promotion that involved the participation of community members improved the coverage of latrines in Mozambique and other African countries. It was further support by DFID, (2002) and the Hesperian Foundation (2005) both noting that latrine promoters should empower community members by enabling them to understand the importance of latrines including the relationship of latrines and their health and dignity.

\section{Community motivating factors}

This study revealed that community members are not motivated towards the construction of household latrines and that there is little initiative to motivate their active participation in latrine promotion activities. This was vividly noted by the elderly FGD respondents. They indicated that some of the community members who have latrines and know about their importance could not educate their fellow community members. It was further learnt that some people scorn fellow community members who try to educate them on the importance of latrines. This lack of motivation was reported to be related to culture, beliefs and taboos which are discussed in more detail below. Another reason given for the lack of motivation for latrine construction was the traditional alternatives used by the community. For example, the presence of banana plantations and bushes is seen as an advantage as they provide privacy, and this is where some people hide themselves to defecate. Moreover, community members lack technical assistance and guidance on household latrine promotion issues.

This funding is supported by most of the researchers revealed that where community motivation was done properly; it improved the coverage of latrines. For instance Sah and Negussie (2008) proposed that latrine promoters should motivate community members to understand the importance of latrines and shift them from subsidised to self-funded latrine promotion programmes. Furthermore, they recommended that latrine promoters should promote social changes that would enable 
community members to declare their villages as Open Defecation Free (ODF). WSP (2004) also argued that in latrine promotion interventions, routine measures cannot address latrine problems because they relied on outdated approaches. Arbelol (1994, as cited by Sitt, 2005) suggested that community members must participate in the initiation and organisation of their latrine promotion programmes.

\section{Economic status}

This study confirmed that their poor economic status contributed to the low coverage of household latrines. Elderly FGD respondents were of the opinion that some of the latrine construction materials require funds which most of the families in the Kagera Region cannot afford. It was further noted by the elderly FGD respondents that some people do not have decent houses and it was therefore naive to consider that people would allocate a portion of their meagre funds to latrine construction. This was also acknowledged by the in-depth interview respondents who agreed that poor economic status hinders some community members from owning latrines because they cannot afford the construction costs. The study also revealed that in some areas special technology and equipment was needed to break rocks or deal with sandy soils in order to construct latrines. The cost of this technology is too expensive for poor households. However, a few FGD respondents observed that because community members lack awareness about the implications of poor sanitation, they are not motivated to prioritise latrines. Instead, they give priority to non-essential luxuries such as alcohol and cosmetics rather than allocating funds to the construction of latrines. The issue of poverty and latrine was earmarked by other researchers that poor economic status is among the factors that contribute to poor sanitation, particularly with regards to household latrines. Mukwaya and Kusiima (1998); Munro, et al. (1991) in Uganda and Pattanayak et al. (2009) in Irissa India revealed the relationship between low economic status on the coverage of household latrines. The UNDP (2012) also highlighted that in Sub-Saharan Africa, access to sanitation was highly correlated with wealth. UNICEF and other development partners in Ethiopia (2009) suggested the consideration of economic status by motivating that affordable types of latrines are advocated during sanitation promotion

\section{Culture, beliefs and taboos}

This study revealed information which concurs with the examples taken from various literatures. The elderly FGD and WDC respondents in particular, reported that there are some cultural beliefs and taboos which account for the low coverage of household latrines. For example, the respondents indicated cultural factors, beliefs and taboos which dictate that children's faeces should not be put in adult latrines, and that some members of the family should not share latrines. This means that people have to opt for unsanitary faecal disposal, such as bush defecation, sharing of open pits with children and disposing of faeces on banana stems. According to respondents' views, these factors, to some extent, contribute to the low coverage of household latrines. However, officials at district levels argued that the cultural and traditional beliefs are outdated and that they no longer affect the ownership of latrines. This means that, despite the view of the communities, measures are unlikely to be taken by district latrine promoters to address cultural factors, and so this will remain an obstacle to latrine coverage. The finding was supported by other researchers. For instance, WaterAid and Ayele (2005) reported that in Ethiopia, cultural beliefs inhibited the uptake of household latrines because they dictated that people should prevent misfortunes by not owning latrines..

\section{The involvement of women (gender)}

This study revealed that gender inequality in latrine promotion contributes to the low coverage of household latrines in the Kagera Region. The respondents stressed that married women are not involved in latrine construction hence limiting their contribution to latrine promotion activities. This however, did not apply to all women. It was also noted that there are some female-headed households who have managed to construct latrines while some male-headed households have not. Those who argued that the low involvement of women affects the coverage of latrines noted that the construction 
of latrines in the Kagera Region is considered to be the duty of men and that some families may fail to own household latrines as the men do not consider constructing them as a priority. Involvement of women has been insisted by various authors. For instance, the WHO (2010) and Stitt (2005) noted that women are the primary caretakers of latrines and so the effects of not involving them in latrine promotion has a negative impact in improving sanitation coverage. The Hesperian Foundation (2005) added that leaving women out of sanitation planning puts them at a greater risk of health problems and other consequences that increase their burden such as caring children suffering from diarrhoeal diseases. Emphasising the involvement of women in latrine promotion, the Hesperian Foundation (2005) stressed that because women are family caretakers their involvement in the promotion of household latrines will safeguard the community. UNICEF (2010) also reported the advantages of involving women by giving an example from Koraput in India where women played an impressive role in raising the household latrine coverage to 100 percent.

\section{The role of latrine promoters}

The current study exposed many aspects where weaknesses exist. From the findings, it was evident that almost all latrine promoters are not fulfilling their roles. They were reported to be weak in terms of numbers, where one health officer is responsible for a large catchment area. In addition, they do not have the resources required to support their work, for example, transport and demonstration materials. They were also reported to lack technical capacity. Moreover, it was learnt that their approach to latrine promotion includes the use of inappropriate measures such as penalising people with no latrines for outbreaks of cholera and typhoid. Though these measures may be useful in forcing people to have latrines, they are not friendly, motivational or educational. Importantly, it was revealed by this study that there were no plans in place to improve the situation.

Furthermore, it was learnt from the FGD respondents that their leaders and health experts are not taking proper action. The elderly FGD respondents claimed that not a single meeting was organised by latrine promoters to discuss the issue of latrines. They also said that there is little attention given by district planners to educating community members on the importance of latrines and that latrine promoters at ward level get little support. The higher levels of government were also criticised. During an in-depth interview, an official from the district blamed colleagues at the district level for not giving adequate attention to latrine promotion. This indicated a relationship between low latrine coverage and inadequate involvement of latrine promoters, particularly from district level.

Another weakness described was the emphasis on addressing the outcomes of the low coverage of latrines by putting more attention on curative services without educating the community members as part of preventive measures. Respondents also reported that latrine promoters directed more effort towards public latrines than household latrines. This is a weakness that was also reported by the World Health Organisation (undated) who argued that by concentrating on societal public latrines, less attention is paid to household latrines and this leaves community members with little knowledge of the importance of household latrines. The focus and actions of latrine promoters reported above may be due to their low capacity in terms of skills and knowledge on how to address or promote latrine construction appropriately. Limited capacity of promoters in this study can be contrasted with the success in Mozambique, as reported by the Ministry of Foreign Affairs of the Netherlands (2012). The African Ministry Council on Water (2011) also reported success in African countries such as Tanzania, Uganda, Ghana and Rwanda where latrine promoters were key facilitators in the Total Sanitation Marketing project, which involved the decentralisation of policies that improved household latrine coverage. In additional, this is a weakness that was also reported by the World Health Organisation (undated) who argued that by concentrating on societal public latrines, less attention is paid to household latrines and this leaves community members with little knowledge of the importance of household latrines. The focus and actions of latrine promoters reported above may be due to their low capacity in terms of skills and knowledge on how to address or promote latrine construction appropriately. 


\section{The role and capacity of community leaders}

As regards the capacity and role of community leaders, such Ward Executive Officers, Village Executive Officers and village Government leaders the study revealed that their capacity is low and that they are not fulfilling their role in latrine promotional activities. Elderly FGD respondents stressed that community leaders including Ward Health Officers, Ward Executive Officers and Village Executive Officers are not involved in latrine promotion. The respondents further asserted that some government leaders who are supposed to enforce environmental laws that demand community members to construct household latrines, either have no latrines or have substandard ones themselves. They therefore doubted how such leaders could promote latrines while they themselves are not seen to value them. From this study, it was discovered that the low capacity among the community leaders, which includes low technical capacity and a limited understanding of their roles and responsibilities, is one of the factors which prevents them from taking an active role in latrine promotion. For instance, Ward Executive Officers and Village Executives Officers are in charge of ward and development teams whose members have different expertise. As most of these wards and village officers do not have relevant qualifications it is difficult for them to provide technical guidance or support to different sectors.

As discussed above, the lack of adequate support from district level was a major challenge. For example, it was revealed in this study that there were neither demonstration materials for latrine construction at ward levels nor transport facilities for the ward health officer who is involved in latrine promotion. Another weakness which was revealed at district level was that latrine promotional activities have been left to the health department and fall only in the environmental cluster. This means that promotional activities lack integration across different sectors. There is no multi-sectorial or intra-sectorial collaboration. This is against the principle of Primary Health Care (PHC) which stresses that PHC strategies should be cost effective, integrated programmes (WHO, 1988). Furthermore, the authors insisted that PHC should be a multi-sectorial collaboration, and requires an approach of community participation and decentralisation of the district health system through integrated and coordinated efforts. The effectiveness of integrated efforts was reported by the African Ministry Council on Water (2011) as a key factor that had led to the success stories of improved latrine coverage in African countries such as Uganda, Ghana and Rwanda.

\section{The role of political leaders}

The study revealed inadequate political will and poor commitment to latrine promotion activities. All FGDs and in-depth interview respondents were disappointed with unwillingness and inactivity of political leaders from village and ward levels in latrine promotion programmes in the Kagera Region. It was expressed by respondents that village chairpersons and councillors are inactive and do not participate as expected. At the village level, the study revealed that some leaders go for 'cheap' popularity by not enforcing environmental laws in order to win votes. It was further noted by respondents that political leaders at district and regional levels concentrate on issues which benefit them politically in preference to latrine promotion. The same was observed by Sah and Negussie (2008) who showed that between 1990 and 2000 approximately 15.7 billion USD was invested annually in the global water and sanitation sector but little of this was invested in sanitation due to lack of political will. Feachem (1980, as cited by Sitt, 2005) argued that though all countries might be encouraged to increase their annual investment in water and sanitation, the effort is negatively affected by weak political commitment. The weak political commitment applies in other contexts as well. For instance, Feachem (1980, as cited by Sitt, 2005) argued that though countries might be encouraged to increase their annual investment in water and sanitation, these efforts will be based on weak existing political commitment. The author gave an example of the Tafae Provincial Ministry of Health which failed to sustain a health programme handed over to them by the donor due to lack of political commitment. WaterAid (2005) in Ethiopia noted that due to inadequate political will, the local government did not allocate funds for latrine promotion and there was no policy framework for 
Texila International Journal of Public Health

Volume 4, Issue 4, Dec 2016

material subsidies in the household latrine construction schemes. The global implication of limited political commitment, as noted by the WHO and UNICEF (2006), is the factor for slow progress towards achieving MDG7

\section{Latrine promotion strategies}

The findings from this study in the Kagera Region showed that the strategies used by latrine promoters often achieved the opposite of what they were designed to achieve. It was revealed that the strategies used in the Muleba District contributed, to some extent, to the low coverage of household latrines because they were inconsistent and/or promoted latrines that community members could not afford. Yet the WDC and VDC members claimed that to some extent they are involved in providing education about latrines, by giving monthly health talks at the dispensary of the out patients department. This type of health education by WDCs and VDC is not adequate to raise awareness and enable the participation of community members in sanitation promotion. Furthermore, it was found that the respondents from the WDCs claim to have been facilitating the implementation of routine health education sessions on the importance of latrines and house to house inspections, yet the elderly FGD respondents claimed not to know about the type of latrine being promoted. This indicated a difference between the perceptions of latrine promoters (WDC and VDC) and the elderly members of the community. Furthermore, as their involvement appeared to be fragmented and unsystematic, it was unlikely to have a tangible impact. For example, giving one health talk a month was unlikely to contribute to the improvement of latrine status. District respondents also revealed that they had previously mobilised communities through meetings at village and institutional levels such as schools, but this was no longer done as it was donor dependent and it is not incorporated in district plans. These examples show how ineffective strategies from latrine promoters contribute to the low coverage of latrines in the Muleba District. The role of latrine promotion stratagies was also urged by other researchers: For instance, the Hesperian Foundation and UNDP (2005) suggest that some experts believe that health problems resulting from poor sanitation can be contained only if people change their behaviour in regard to hygiene. However, these ideas often fail because they do not consider the barriers which people face, such as poverty and other social and cultural factors. Another aspect is the focus on technical solutions (UNDP, 2005) such as modern toilets with flush water systems, but these may not be feasible under the prevailing conditions in the community and may create more problems than they solve

\section{Conclusions}

The exploration of the perceptions of community members and latrine promoters revealed a myriad of interrelated factors that impact on the low coverage of household latrines in the Muleba District. The respondents recognised the importance of the study topic and the importance of household latrines though they acknowledged that it was not usually given the attention required. Factors affecting the coverage of household latrines were revealed from the study respondents and from the information in the literature. The factors identified include community involvement, the capacity of community leaders and latrine promoters, economic status, gender considerations, cultural beliefs and taboos, political will and latrine promotion strategies. In addition, several suggestions were put forward by respondents about possible solutions to solve the problem of the low coverage of latrines; these also complied with the proposed measures that arose from the literature. The recommendations that follow are based on a combination of the factors and suggestions put forward by the respondents and the insights that emerged from the discussion chapter of this study. 


\section{Recommendations}

Community at community level: In order to ensure community involvement latrine promoters should put strengthening and enabling community members to be actively participation in the promotion of sanitation. This means that there should an increase in number of sensitisation sessions at community level.

At Promoters level: The Ministry of Health and Social Welfare, the Regional Health Management Team (RHMT) and the Council Health Management Team (CHMT) to develop and implement capacity building programmes for the key latrine promoters on identified above issues as follows.

In order to adress poor economic status: Latrine promotion programmes should consider the economic issues in order to find the means to support community members who are unable to construct latrines due to economic constraints. For instance, a subsidy scheme for the construction of a latrine can be introduced while building the capacity of a community member for sustainability

About Gender Considerations: It is recommended that latrine promoters should incorporate gender mainstreaming in latrine promotion and enable both women and men to take an active role in latrine promotion programmes.

Cultural Beliefs and Taboos: Promoters have to seriously consider these identified these factors and work closely with community to adress them

Concerning Political will: It is recommended that political mobilisation should be one of the components in latrine promotion

In relation to latrine Promotion Strategies: It is recommended that the strategies chosen have to be more user-friendly, practical and affordable for the majority of community members.

\section{References}

[1] Africa Minister's Council on Water, EUWI and UNDP, (2006). On Track to Meet the MDGs on Water and Sanitation: A Status, Overview of Sixteen Africa Countries.

[2] Cameron, L., (2009). Household pit latrine and child health in rural Ethiopia. Department of International Development, Young Lives, University of Oxford, United Kingdom.

[3] Chaggu, E., (2009). Sanitation Sector Status and Gap Analysis. Dar es Salaam, Tanzania.

[4] DFID, (2002). Water supply and Sanitation in DFID Programme and Project Cycle. [Online]. Available: www.lboro.ac.uk/well/resources/publications/guidance/overview.pdf'[Accessed: 12/04/2012: $6.22 \mathrm{PM]}$

[5] Diallo, M. O., Hopkins, D. R., Kane, M. S., Niandou, S., Amadou, A., Kadri, B., Amza, A., Emerson, P. M. and Zingeser, J. A. (2007). Household latrine use, maintenance and acceptability in rural Zinder. Niger International Journal of Environmental Health Research. Volume 17, Issue 6.

[6] End Water Poverty, (2010). A Programme for action: tackling the sanitation crisis. [Online]. Available: www.endwaterpoverty.org [Accessed: 8/03/2012: 6.45 PM]

[7] End Water Poverty, (2010). Sanitation and Water For All. [Online]. Available: www.endwaterpoverty.org [Accessed: 8/03/2012: 5.45 PM]

[8] Guion, L., (2006), Department of Family, Youth and Community Science, Cooperative Extension Service, IFAS, University of Florida, Gainesville, USA. [Online]. Available: http://edis.ifas.ufl.edu/FY393 [Accessed: 28/01/2012 7.30 PM].

[9] Hesperian Foundation, (2005). Sanitation and cleanness for a healthy environment [Online]. Available: http://www.hesperian.org. [Accessed: 12/01/2012 12.30 PM].

[10] Krumeich, A., Weijts, W., Reddy, P. and Meier-Weitz, A. (2001). The Benefits of Anthropological Approaches for Health Promotion Research and Practice. Health Education Research, 16(2): 121-30.

[11] McCullough, L. (2005). Women, Water and Hygiene are Key to Change in Africa. [Online]. Available: http://unicef.org/media/media_28260.html [Accessed: 29/03/2011 4.00 PM]

[12] Mukwaya, R., Kusiima, B.A. (1998). Community use of pit latrines in Mubende District, Uganda. Basic Services Fund, South Sudan. 
Texila International Journal of Public Health

Volume 4, Issue 4, Dec 2016

[13] Muleba District Council, (2011). Council Comprehensive Health Plan 2011/12. Tanzania.

[14] National Bureau of Statistics Tanzania (2010). Demographic and Health Survey. Dar es Salaam, Tanzania.

[15] Pattanayak, J. K., Yang J.C., Dickinson, K. L., Poulos, C. V., Patil, S. R., Mallick, R. K., Blitstein, J. L. and Praharaj, P. (2009). Shame or subsidy revisited: social mobilization for sanitation in Orissa, India. [Online]. Available: www.who.in/entity/bulletin/volumes/

[16] 87/8/08-057422/en/-54k [Accessed: 29/03/2011 3.00 PM].

[17] Population Service International (2004) The Prevalence of Diarrhoea In Tanzania, [Online] : http://www.psi.or.tz/our-works/safe-water.php

[18] RS and RHMT, (2011). Strategic Plan July 2010-June 2015. Regional Commission’s Office, Kagera Region, Tanzania.]

[19] Santakar, C. (2010). Achieving one hundred per cent individual household latrines coverage. [Online]. Available: www.unicef.org/india/reallives_6129.htm [Accessed: 5/06/2012 3.00 PM]

[20] Schaay N. and Sander, D., (2006). International Perspective on Primary Health Care over the past 30 years. School of Public Health, University of the Western Cape, South Africa.

[21] Stitt.T. (2005). Evaluation of rural sanitation program in Vanuatu with management recommendations. Journal of Rural and Tropical Public Health 4: 1-9 (2005)

[22] Tibaijuka. A, (2010). Gender Equity and Sanitation. Opening Statement at the UNHABITAT Gender Quality Action Assembly. Brazil.

[23] UNIAIDS, (2011). UN-Women Gender Equality and HIV/AIDS, New York. Email: genderandaids@ unwomen.org

[24] UNDP Human Development Report, (2006). Beyond scarcity, Power, poverty and global waste. [Online], Available: http://hdr.undp.org/en/media/HDR_2006_Chapter_1.pdf [Accessed: 19/12/2012 8.40 PM]

[25] UNDP, (2012). The Millennium Development Goals Report 2012. [Online]. Available: http://www.un.org/millenniumgoals/pdf/MDG\%20Report\%202012.pdf [Accessed: 14/ 12/2012 2.58 PM]

[26] UNICEF, (1998). A Manual on School Sanitation and Hygiene. Water Environment and Sanitation Guidelines, Series No 5. New York. [Online]. Available: http://www.unicef.org [Accessed: 14/ 12/2012 1.30 $\mathrm{PM}]$

[27] UNICEF and Development in partners, (2009). Technical Guidelines for the Construction and Management of Household latrines. A Manual for Field Staff and Practitioners. [Online]. Available: http://www.bsf-south-sudan.org/sites/default/files/SS+Tech+Guide--Household+Latrines.pdf

[Accessed: 12/12/2012 7.11 PM]

[28] United Republic of Tanzania, (2006). Monitoring Master Plan and Indictor information. Poverty Eradication Division, Ministry of Planning, Economy and Empowerment, Dar es Salaam, Tanzania.

[29] United Republic of Tanzania (2007). Poverty and Human development Report. Ministry of Planning, Economy and Empowerment, Mkuki nyota publisher, Dar es Salaam, Tanzania. [Online]. Available: www.povertymonitoring.go.tz [Accessed: 3/03/2012 4.15 PM]

[30] United Republic of Tanzania, (2009). Supplement to the Public Health Act 2009. Dar es Salaam, United Republic of Tanzania.

[31] United Republic of Tanzania: Ministry of Health and Social Welfare and Prime Minister's Office Regional Administration and Local Government, (2008). Functions of Regional Health Management System. Roles and Responsibilities of Regional Health Management Team, Regional referral Hospital Management Team and Regional Health Referral Board

[32] Water and Sanitation Program (WSP), (2004). Who Buys Latrines, Where and Why? Sanitation and Hygiene Field Series, Field Notes. Nairobi, Kenya.

[33] Water and Sanitation Program (WSP) Africa Region, (2008). Country Status Overview - Regional Synthesis Report Pathway to progress. Transition to Country Lead Service Delivery Pathways to Meet African's Water Supply and Sanitation Targets.

[34] Water and Sanitation Program (WSP), (2010). Country Profile Series. Dar es Salaam, Tanzania. [Online]. Available: www.wsp.org [Accessed: 6/03/2012 5.30 PM] 
[35] Water and Sanitation Program (WSP), (2011). Case study, Getting Africa to meet the Sanitation MDG. Lesson from Rwanda. [Online]. Available: http://www.wsp.org/sites/ wsp.org/files/publications/wsp-rwandasanitation-lessons.pdf [Accessed: 17/9/2012 12.44 PM]

[36] Water and Sanitation Program (WSP), (2011). Scaling up Rural Sanitation, Enabling Environment Endline Assessments. Dar es Salaam, Tanzania.

[37] Water and Sanitation Program (WSP), (2011). Financing Household on-site Sanitation for the Poor. [Online]. Available: http://sanitationupdates.wordpress.com [Accessed: 5/02/2012 3.00 PM]

[38] WaterAid and Ayele, (2005). Water is life, Sanitation is Dignity, Sanitation preference and Household latrine Designs, Briefing Note 1. WaterAid, Ethiopia.

[39] WHO and UNICEF, (2006). Meeting the MDG drinking Water and Sanitation Targets: The Urban and Rural Challenges of the decade, Geneva. Switzerland.

[40] WHO and UNICEF, (2008). Join monitoring Programme for water supply and sanitation, The UN mechanisms for accessing progress.

[41] World Bank, (2006). India Water and Sanitation, Bridging the Gaps between Infrastructure and Services. Background Paper on Urban Water Supply and Sanitation

[42] World Health Organisation, (1978). Declaration of Alma Ata, International Conference on Primary Health Care, Alma Ata, USSR: 6-12 September 1978.

[43] World Health Organisation, (1978). Primary Health Care, Report of International Conference on Primary Health Care, Alma Ata, USSR, 6-12 September 1978: 43-48.

[44] World Health Organisation, (2005). Sanitation challenge: Turning commitment into reality. [Online]. Available: www.who.int/water_sanitation_health/hygiene/envsan/sanitchallenge/en/ index7.html [Accessed: 30/3/2012 3.05 PM]

[45] World Health Organisation, (2010). Monitoring of the achievement of the health related Millennium Development Goal. Report by Secretariat. Sixty-Third World Health Assembly.

[46] World Health Organisation, (undated). The Right Fit: Are Our Institutions Up to the Job? [Online]. Available: www.who.int/entity/water sanitation/hygiene/securingsanitation3.pdf [28/3/2012: 4.30 PM]

[47] World Health Organisation, (2012). UN-Water Global Analysis and Assessment of Sanitation and Drinking Water. The Challenge of Extending and Sustaining Services. Geneva, Switzerland

[48] World Health Organisation, (2012). Health promotions, Milestones in health promotions. Statements from global conferences: The OTTAWA character for health promotion, First International Conference on Health Promotion, OTTAWA 17-21 November, 1986.

[49] Werner, D. (1995). Who Killed Primary Health Care? "How the ideal of health for all was turned into the reality of worsening health for the world's poor.” The New Internationalist, 1995. 